\title{
On the use of duplex stainless steels in bridge construction
}

\author{
O. Hechler \\ ArcelorMittal Commercial Sections S.A., Technical Advisory, Luxembourg former \\ RWTH Aachen University, Lehrstuhl für Stahlbau und Leichtmetallbau, Gemany \\ P. Collin \\ Lulea University of Technology, Division Structural Engineering, Sweden
}

\begin{abstract}
Maintenance and the related costs in the life time of existing structures are an ever growing problem and bridges are no exception to this rule. Much of the maintenance costs are related to corrosion of steel members. Especially when steel and composite bridges are built in aggressive environments (e.g. close to seawater or in industrial atmospheres) these costs become of major importance. However also concrete bridges are concerned as the re-bars in concrete decks may be subjected to corrosion caused by chloride ingress from de-icing salt or seawater. Consequently the use of a material providing high mechanical properties with a sufficient corrosion resistance for the application in these aggressive environments would lead to economic and durable construction. Further the maintenance costs become predictable, which would increase the quality of the bridge management.

Duplex stainless steel is this material with sufficient yield strength, stiffness and toughness as well as an excellent durability in aggressive environments. With a targeted material choice, innovative construction solution may be achieved. However, high material costs, gaps in common knowledge, e.g. on fatigue, as well as fabrication aspects are preventing a wider application of these steels in bridge construction.
\end{abstract}

\section{INTRODUCTION}

\subsection{Motivation}

The deterioration process for infrastructure projects built in concrete is one of the major challenges in the near future. In 1998 a study in the USA has revealed that at these days more than 600000 road bridges had to be refurbished for about US\$200 Billions. The costs for the refurbishment had been determined to be 4 times higher than the building costs [Whiteway 1998]. In most parts of the world the same conditions are to be expected.

One reason for these circumstances is the belated realisation of the corrosion phenomenon for reinforcing steel in concrete bridges subjected to atomic spray containing chlorides. Although rules for the closure of the bridge surface exist starting with the Hessensiegel in Germany since the early 80ies leading to Standardisation with the ZTV-ING 2006 and TL/TP-BEL-B 1999 the concrete surfaces under and on the sides of the bridge subjected to water splash and atomized spray have not been strictly considered. The concrete cover according to the DIN 1045: 1972 and 1078 of $3 \mathrm{~cm}$ has been identified to be far to low. Therefore it has been increased in the DIN 1045: 1988 for components subjected to de-icing salt spray to already $4 \mathrm{~cm}$. However the application scope of the increased concrete cover and reduced w/c-values has for the first time been strictly defined in the DIN 10452001 and is now supposed to be sufficient for these concrete components. An alternative approach with the use of stainless steel reinforcement is shown in Chapter 2.1.

Steel bridges are protected against corrosion via the application of organic coatings. These coatings are applied on the steel surface outside as well as inside of the structure respectively 
closed sections have to be continuously dehumidified. With a relative humidity smaller than $40 \%$ the corrosion will not take place.

In general corrosion systems are applied which are standardized according to the EN ISO 12944. These systems are designed in respect to the required duration until the corrosion system has to be maintained (low [K, 2-5 years], medium [M, 5-15 years], high [L, > 15 years]) and five corrosion categories from $\mathrm{C} 1$ to $\mathrm{C} 5$ depending on the corrosive atmosphere, in which the bridge is situated.

The corrosion protection for steel in bridges in the category $\mathrm{C} 5$ is excessive in fabrication. For external surfaces the surface has to be prepared and about 4 coating layers have to be applied (see e.g. Geholit+Wiemer 2007); normally the basic layer and two medium layers by a machine and the finishing layer by hand. For internal surfaces the protection system may be reduced to two layers. Of course the anti-corrosion system and corresponding price depends on the maintenance intervals and the corrosion category.

Due to the multiple layer design, drying times have to be respected in fabrication, which cause delay and space for the drying beams is needed. Further the protection system can be damaged due to the transport and erection leading to claims as well as expensive and time consuming reparation on site. If welding has to take place on site, the steel members are partly not protected during construction and the protection system has to be applied subsequent on side.

It has to be noted that with the acceptance to invest money corrosion is a well controlled phenomenon for steel bridges.

However Duplex stainless steels, e.g. EN 1.4462 of EN 10088, do not need any corrosion protection and can be applied in environments with category C5 without any corrosion maintenance to be expected [Z-30.3-6]. Although the welding techniques have to be appropriate for the application [RFS-CR-04040].

Therefore bridges built of Duplex stainless steels may provide an interesting alternative to concrete bridges and bridges in carbon steel, see chapter 2.3. This is especially the case in areas where recurrent sandstorms may damage an anti-corrosion system or where a closure of the bridge for maintenance reason is economically unacceptable (e.g. bridges in highly frequented harbour areas).

Up to now it is not possible to design a bridge using duplex stainless steels according to the Eurocodes. While both EN1993-2 and EN1993-1-9 contain the fatigue design criteria for welded structural details made of carbon steel, supplementary rules for stainless steel are given in the EN1993-1-4. Although these criteria are extended to some austenitic and duplex stainless steel grades, they are not applicable to all the welded structural details met in the bridge construction. In chapter 4 , the fatigue design of critical bridge details made in duplex stainless steel are investigated and design guidance is given on the basis of the presented research results.

\section{THE USE OF DUPLEX STEEL IN BRIDGE CONSTRUCTION}

\subsection{The use of stainless reinforcement}

The corrosion of reinforcing steel in concrete structures is a growing problem facing the owners as they maintain an ageing and deteriorating infrastructure. One of the main causes of corrosion of steel in concrete is chloride ingress from de-icing salt or seawater. The usual solution to the corrosion problem is to ensure a concrete cover of high quality and adequate thickness leading to strict requirements to the concrete mix design and the execution of the concrete work, see chapter 1. In some cases, these requirements are combined with surface treatment to minimise chloride ingress. If corrosion damage has already developed, the traditional repair and rehabilitation options include the conventional physical techniques of concrete repair, patching, overlaying and coating as well as the electrochemical techniques of catholic protection, chloride removal and realkalisation. 


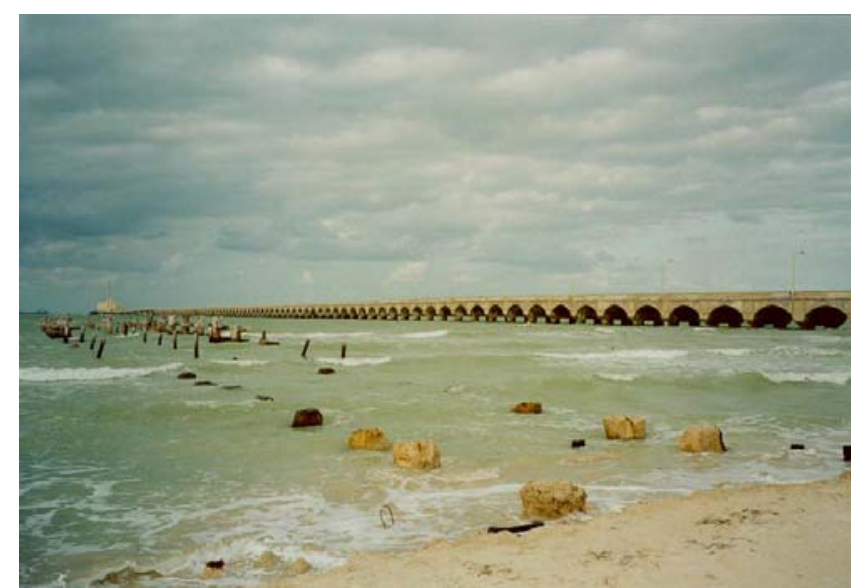

Figure 1. Progresso Pier built with stainless reinforcing steel in the late 1930s (right) and the remainings of a parallel neighbour pier with ordinary carbon steel in the 1960s (left).
Despite the fact that stainless reinforcing steel with a much higher chloride tolerance than the ordinary carbon steel reinforcement is available today, stainless reinforcing steel is still not frequently applied in the critical areas with severe chloride exposure in new concrete structures or in repairs of corrosion damaged concrete structures.

The limited use of stainless steel in new structures and repairs is usually attributed to the relatively high initial cost of the stainless steel compared to carbon steel. However, the limited long-term experience with stainless steel in chloride contaminated concrete compared to ordinary carbon steel may also have contributed.

For repairs, an additional reason may be worries that the connection between stainless steel and carbon steel will lead to galvanic corrosion on the less noble carbon steel.

\subsection{The use of stainless steel plates}

For the steel girders of a composite bridge, or a pure steel bridge, a possible solution is to use duplex stainless steel. In the following, such a bridge, namely the pedestrian bridge Apaté in Stockholm, is presented.

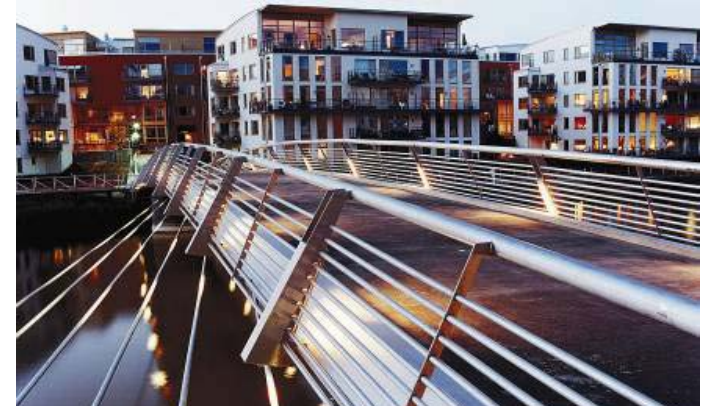

Figure 2. Bridge Apaté in Stockholm.

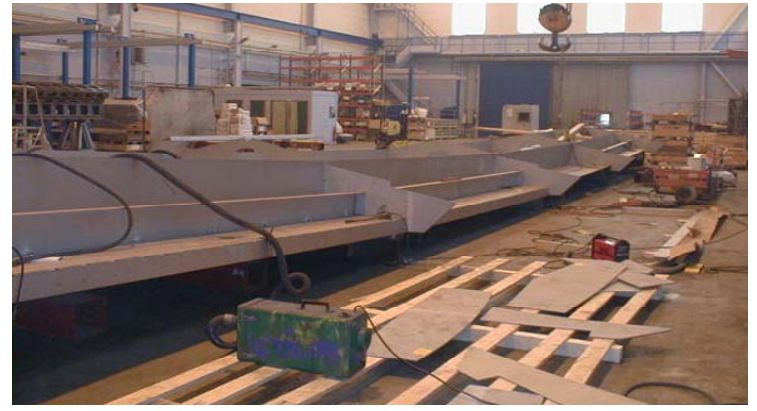

Figure 3. Fabrication in the workshop, where the bridge can be seen lying upside down.

The conceptual design of Bridge Apatê was prescribing one $50 \mathrm{~m}$ arch tied together by steel cables, and one simply supported girder with the span of $10 \mathrm{~m}$. The cross section of the arch was a space truss covered by stainless steel plates.
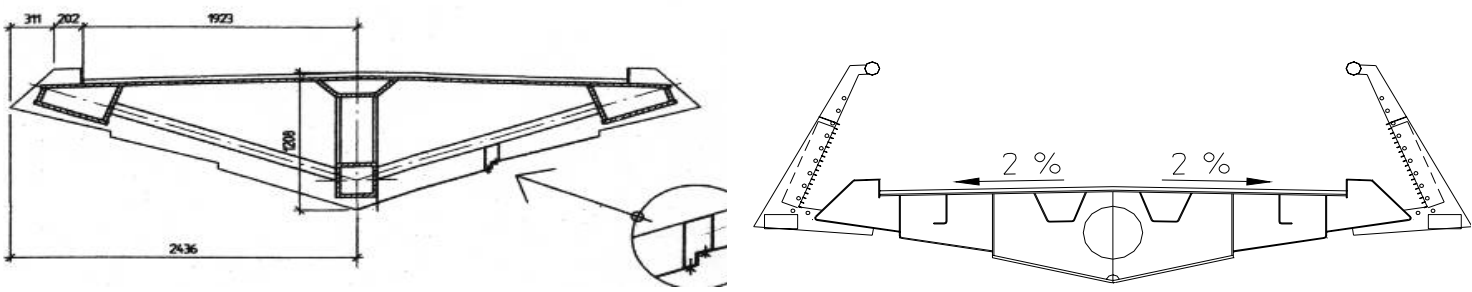

Figure 4. Suggested conceptual design, as well as the design proposed by Ramböll.

The consultant company Ramböll chooses a two-span continuous bridge, with a box cross section. The deck plate was $12 \mathrm{~mm}$ thick, and the bottom flange between $18 \mathrm{~mm}$ and $25 \mathrm{~mm}$. The stiffeners were cold-formed from $8 \mathrm{~mm}$ thick plates. In order to minimize deflections and vibrations at the longer span, the bridge end is prevented from rotating by horizontal shear studs in the concrete at the abutment. 
The steel plates were water cut and welded together using MIG-welding by STÅLAB. The bridge was transported in three $20 \mathrm{~m}$ pieces to be welded together at site, see Fig 3 .

Since the bridge spans are very unsymmetrical, $50 \mathrm{~m}+10 \mathrm{~m}$, the uplifting of the end support had to be prevented. Therefore the pieces were welded together with the mid support $370 \mathrm{~mm}$ over its final position. After the bridge lifted in place, this added extra force to support 3. Furthermore the shorter span was filled with concrete, giving both extra dead weight and extra stiffness.

\subsection{Costs comparison for a three span motorway bridge}

However the final choice for the materials applied mainly depends on the costs. In 2002 Ramböll were given the assignment to design a highway bridge carrying the highway E4 over a national road in mid Sweden [Collin et al. 2002]. Three alternatives were studied, namely

1) A haunched three span I-girder bridge in carbon steel

2) A haunched three span I-girder bridge in duplex stainless steel..

3) An arch bridge in duplex stainless steel

The two last solutions included stainless reinforcement in the concrete deck as well as stainless siderails

Although the bridge was finally constructed in concrete, due to savings in the budget for the road administration during the summer of 2002, calculations and drawings were produced for all solutions. Further a cost comparison was made with help from the same steel contractor that fabricated the bridge Apaté, STÅLAB in Trollhättan.

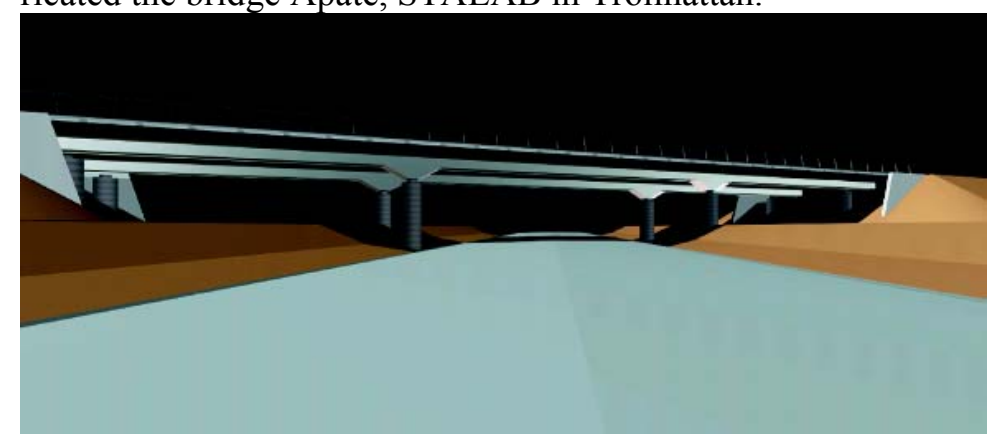

Figure 5. A haunched I-girder bridge carrying highway E4 over a national road.
Since in 2002 stainless steel plates roughly cost three times more than carbon steel, it was no surprise that the stainless steel alternatives were more expansive than the one using carbon steel. Furthermore, the stainless steel arch would have a much higher weight than the I-girder alternatives, since the simply supported cross girders would have to carry the load between the arches.

From the figure below it can be seen that the cost for alternative 1) was estimated to $550000 €$, to be compared with $700000 €$ for alternative 2. One conclusion is that bridges in stainless steel $(1000000 €)$ are unlikely to win market shares before the bridge owners start to include the costs for maintenance in their evaluations of the bridge costs.

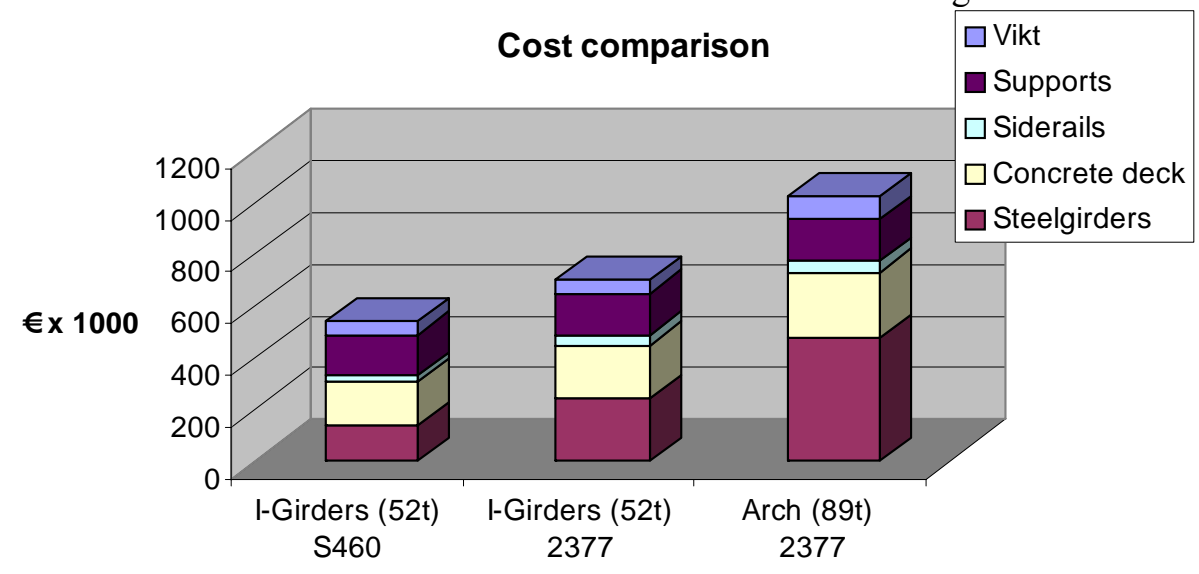

Figure 6. Cost comparison for 3 alternative designs. 
The major cost factor in these maintenance costs is the maintenance of the protection system in the life time. These costs are depending on the frequency of the maintenance action, costs for the coating itself and the related costs e.g. scaffolding, measures for the protection of the environment, etc. A standardized practice is not to be identified; it is varying for each country respectively bridge owner and new procedures and protection systems are invented for special applications. E.g. in Germany the following options are provided by the authorities [RI-WI-BRÜ] for the maintenance of the protection system:

Option 1: 15 DR -10 DR -20 CR -15 DR - 20 DR

Option 2: every 25 years CR

whereas DR: Damage repair of corrosion protection (max. 7\% of the surface area), $\mathrm{CR}$ : Complete renewal of the protection system.

In general the costs for the maintenance of the corrosion protection are about $50 € / \mathrm{m}^{2}$ and for the complete renewal about $100 € / \mathrm{m}^{2}$ [Heinemeyer 2006]. Scaffolding and protection are not included in these costs and may increase them significantly. With option 1 and scaffolding costs doubling the corrosion maintenance costs the total life maintenance costs are determined to 600 $€ / \mathrm{m}^{2}$. Consequently, based on the assumption that all other maintenance costs are constant, duplex stainless steels provide a promising alternative for bridges with a surface to be protected larger than $750 \mathrm{~m}^{2}$ respectively bridges in areas with aggressive environment, where option 1 is insufficient for the protection of the bridge,. In addition the effects on the traffic disturbance during repainting etc. increase the competitiveness of the stainless steel solution [RFS-CR04040].

\section{FATIGUE DESIGN OF DUPLEX STAINLESS STEEL BRIDGES}

However after the economic decision for a duplex stainless steel bridge gaps in current design practice appear. Especially rules for the fatigue design of duplex stainless steel members are not existing.

This chapter is related to the fatigue behavior of most critical constructional details met in welded bridges. This is of large importance as steel bridges are increasingly designed using complex welded steelwork solutions to emphasise the lightness and aerodynamic shaping steel can offer.

In the frame of a research project funded by the EU research programme RFCS (Research Fund for Coal and Steel [RFS-CR-04040] existing test data on the fatigue strength of duplex steel has been evaluated, experimental gaps have been filled and the fatigue categories of welded details made in duplex steel have been statistically.

The duplex stainless steel investigated was the Uranus 45 Nmo produced by INDUSTEEL Creusot, France. The following critical welded details have been selected to be investigated:

(A1) Welded longitudinal attachment (Detail 1, Table 8.4 of EN1993-1-9);

(A2) Transverse butt weld (Detail 5, Table 8.3 of EN1993-1-9);

(A3) Welded transverse attachment (Detail 7, Table 8.8 of EN1993-1-9);

(A4) Rib-to-deck weld (Detail 7, Table 8.8 of EN1993-1-9);

(A5) Transverse butt weld with backing strip (Detail 14, Table 8.3 of EN1993-1-9);

(A6) Shear stud welded on base material (Detail 9, Table 8.4 of EN1993-1-9);

(B2) Joint in rib, full penetration butt weld with steel backing plate (Detail 4, Table 8.8 of EN1993-1-9). 
Table 1. Details made from Duplex stainless steel EN 1.4462.
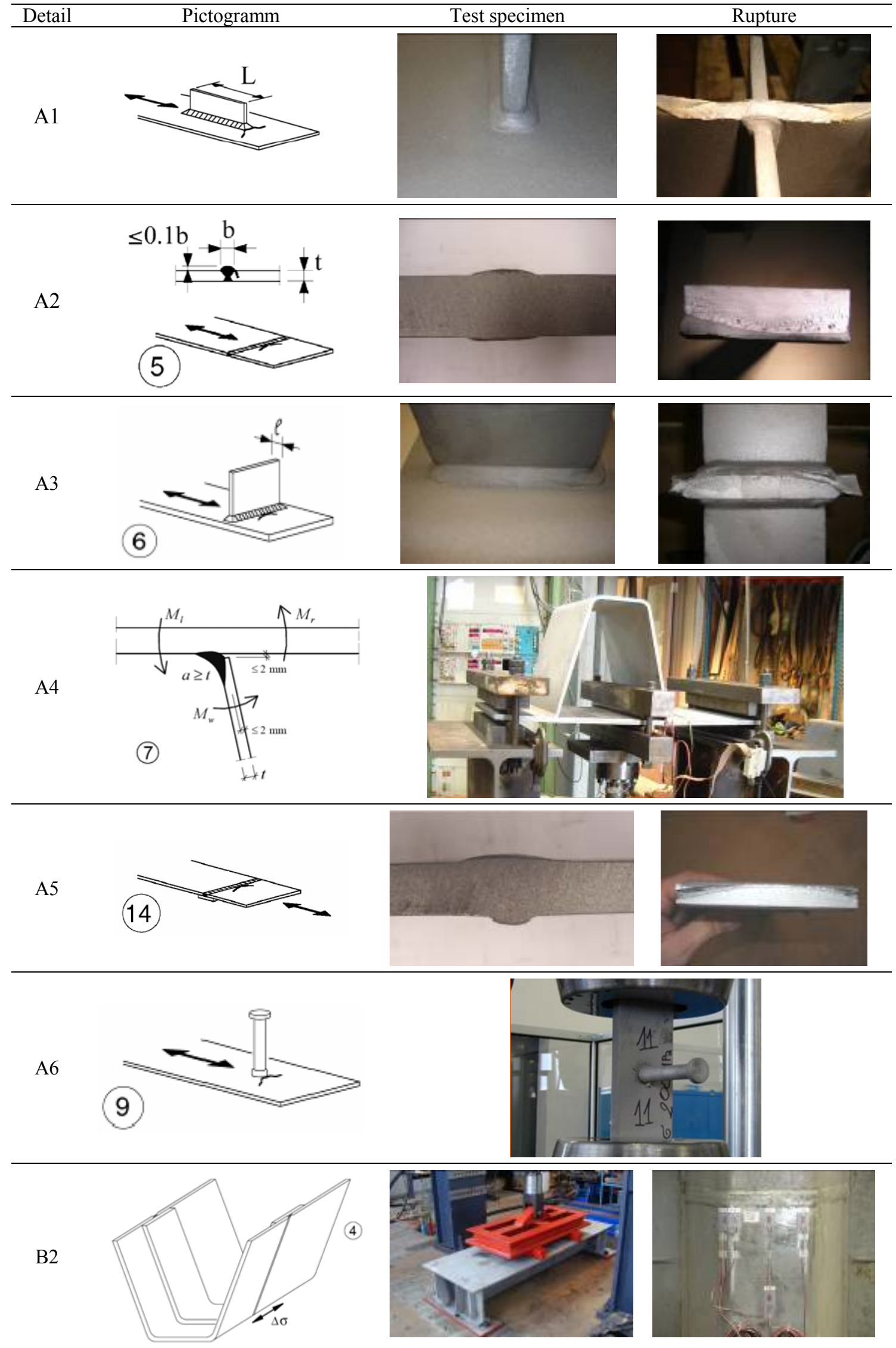
Further a rib-to-cross-beam welded connection with additional cut-out (Detail 1, Table 8.8 of EN1993-1-9) has been investigated but is not included in this paper. Further information can be found in RFS-CR-04040.

Corrosion fatigue resistance of duplex steel is not covered by the present paper however it can be neglected for Duplex stainless steels 1.4462 in the environment assumed [Z-30.3-6].

The results from the literature survey as well as the own tests mentioned above are statistically evaluated in order to determine the relevant S-N curve. For that purpose the reference value of the fatigue strength $\Delta \sigma_{C}$ at $N_{C}=2$ million cycles have been determined based on 2 different approaches:

(1) based on the stresses derived from the cyclic load $\Delta \mathrm{P}$ divided by the area $(\Delta \mathrm{P} / \mathrm{A})$,

(2) based on the stresses derived from measured cyclic strains as follows:

$$
\Delta \sigma_{C, E}=\alpha \cdot \Delta \sigma_{C}
$$

where $\alpha=\mathrm{E}_{\alpha} / 200000$ and

$\mathrm{E}_{\mathrm{a}}$ is the modulus of elasticity used in the static analysis for the calculation of the applied stress range $\Delta \sigma_{\mathrm{i}}$.

The statistical evaluation has been carried out using the linear regression analysis described in Brozzetti et al. 1989 to determine the probability of failure for $50 \%$ and $5 \%$ with respectively variable slope and fixed slope $\mathrm{m}=3$, as adopted in EN1993-1-9. Finally the results of the statistical evaluation are compared to each other and to the detail category given by the EN1993-2.

The fatigue results obtained for duplex steel are compared to the detail categories for C-steel in Table 2.

Table 2. Comparison of evaluation $\left(E=200000 \mathrm{~N} / \mathrm{mm}^{2}\right)$ [Hechler et a1. 2007].

\begin{tabular}{|c|c|c|c|c|c|c|}
\hline \multirow{3}{*}{\multicolumn{2}{|c|}{$\begin{array}{l}\text { Fatigue } \\
\text { strength }\end{array}$}} & C-steel & \multicolumn{4}{|c|}{ Duplex steel } \\
\hline & & - & $(\Delta \mathrm{P} / \mathrm{A})$ & Inc. & $(\Delta \varepsilon \alpha \mathrm{E})$ & Inc. \\
\hline & & $95 \%$ & $95 \%$ & $\%$ & $95 \%$ & $\%$ \\
\hline \multirow{7}{*}{ 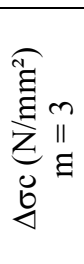 } & A1 & 56 & 72 & 29 & 88 & 57 \\
\hline & $\mathrm{A} 2$ & $87(*)$ & 85 & -2 & 103 & 18 \\
\hline & A3 & 80 & 88 & 10 & 107 & 34 \\
\hline & A4 & 71 & 162 & 127 & 159 & 124 \\
\hline & A5 & 71 & 73 & 3 & 86 & 21 \\
\hline & A6 & 80 & 122 & 53 & - & - \\
\hline & B2 & 71 & 98 & 38 & - & - \\
\hline
\end{tabular}

$(*)$ Size effect considered

The detail category of welded details made of duplex steel is at least equivalent to the ones derived for C-steel.

\section{SUMMARY}

The social acceptance to invest more money for the application of duplex stainless steel in construction of today is based on the architectonical design emphasizing a durable aesthetic. Therefore one aim of this paper was to extend this limited acceptance by economical and ecological considerations for specific applications. Already realised examples have been presented in this paper.

With having in mind the maintenance costs of bridges, duplex stainless steels offer new possibilities for the design of very economic and durable construction for the life-time. One reason why the material has not yet been used more frequently is the lack in design standardisation, e.g. buckling and fatigue. Concerning fatigue the detail category of welded details made of duplex steel is at least equivalent to the ones derived for C-steel. As final conclusion the application of duplex steel in bridge constructions is not depending on the fatigue performance of their joints. The use is depending on the decision of the owner which is mainly based on economic considerations. Therefore a comparative study on the on a design alternative in duplex stainless steel 
for two span bridge has been added to point out the advantages of this material for bridge constructions.

However the higher prize of stainless steel as well as the fact that the steel contractors are not used to make bridges in this material, are quite heavy obstacles to overcome.

\section{ACKNOWLDGEMENTS}

The authors wish to express their deep gratitude to the European Commission for its financial support (Contract RFS-CR-04040) and to the representatives of the other partners from ULg, CSM and INDUSTEEL Creusot for their inspiring cooperation.

\section{REFERENCES}

Whiteway, P. 1998. Building better bridges. Nickel Magazine Sept. 98

ZTV-ING. 2006. Zusätzliche Technische Vertragsbedingungen und Richtlinien für Ingenieurbauten.

TL/TP-BEL-B. 1999. Teil 1 - Technische Lieferbedingungen und Technische Prüfvorschriften für Brückenbeläge auf Beton mit Dichtungsschicht aus einer Bitumen-Schweißbahn nach den ZTV-BELB Teil 1.

DIN 1045. 2001. Tragwerke aus Beton, Stahlbeton und Spannbeton - Teil 1: Bemessung und Konstruktion.

Geholit+Wiemer. 2007. Korrosionsschutz. Geholit+Wiemer Lack- und Kunststoff-Chemie GmBH.

RI-WI-BRÜ. Richtlinie zur Durchführung von Wirtschaftlichkeitsuntersuchungen im Rahmen von Instandsetzungs-/Erneuerungsmaßnahmen bei Straßenbrücken (RI-WI-BRÜ). Bundesministerium für Verkehr, Bau- und Wohnungswesen; Abteilung Straßenbau, Straßen-Verkehr

Heinemeyer, C. 2006. Korrosionsschutz bestehender Stahlbauten. Lehrstuhl für Stahlbau und Leichtmetallbau, RWTH Aachen.

EN 10088. Stainless steels.

RFS-CR-04040. Application of Duplex stainless steel for welded bridge construction in aggressive environment - BRIDGEPLEX. Research Fund for Coal and Steel. 01/07/2004 - 30/06/2007. To be published 2008

EN1993-2. Eurocode 3: Design of Steel Structures. Part 2: Steel Bridges

EN1993-1-9. Eurocode 3. Design of steel structures. Part 1-9: Fatigue

EN1993-1-4. Eurocode 3: Design of Steel Structures. Part 1-4: General rules. Supplementary Rules for Stainless Steel

Z-30.3-6. 2003. Allgemeine bauaufsichtliche Zulassung. Erzeugnisse, Verbindungsmittel und Bauteile aus nichtrostenden Stählen.

Brozzetti J., Hirt M.A., Ryan I., Sedlacek G. and Smith I.F.C. 1989. Background Informations on Fatigue Design Rules - Statistical Evaluation. Centre Industriel de la Construction Métallique, Ecole Polytechnique Fédérale de Lausanne and RWTH Aachen University, Institute of Steel Construction

Hechler O., Feldmann M., Maquoi R. 2007. Fatigue design of bridge construction made in duplex stainless steel. Proceedings of The third international conference on structural engineering, mechanics and computation (SEMC 2007). Cape Town, South Africa.

Collin P., Lundmark T. 2002. Competitive Swedish Composite Bridges. IABSE Symposium Melbourne.

EN ISO 12944. 1998. Beschichtungsstoffe - Korrosionsschutz von Stahlbauten durch Beschichtungssysteme. 